\title{
Humor Types Show Different Patterns of Self-Regulation, Self-Esteem, and Well-Being
}

\author{
Anja K. Leist • Daniela Müller
}

Published online: 12 May 2012

(C) The Author(s) 2012. This article is published with open access at Springerlink.com

\begin{abstract}
Humor styles have been found to be associated with well-being, however, no study has addressed the distinct well-being associations of combinations of humor styles, that is, humor types, yet. The present study thus aimed at investigating which combinations of humor styles exist and to which extent these humor types are associated with well-being. In an online questionnaire, the Humor Styles Questionnaire (HSQ, Martin et al. J Res Pers 37:48-75, 2003), self-regulatory strategies, self-esteem, and well-being instruments were administered to a German sample. Exploratory and confirmatory factor analyses replicated the underlying structure of the HSQ. With hierarchical clustering, we found evidence for three humor types (endorsers, humor deniers, and self-enhancers), which differed in group means for self-esteem, self-regulatory strategies, and well-being. Findings provide further evidence for the positive well-being correlates of self-enhancing humor, and distinctly address the positive correlates of aggressive and self-defeating humor being absent. It is discussed that humor styles cannot be conceptualized as beneficial or detrimental per se, but have to be regarded in context.
\end{abstract}

Keywords Humor styles $\cdot$ Self-esteem $\cdot$ Self-regulation $\cdot$ Well-being

\section{Introduction}

It is widely believed that humor is an important resource for well-being. Confronted with a difficult life situation, a German saying goes "have a sense of humor" and reveals the implicit assumption that making jokes or enjoying absurdities of current life circumstances

\footnotetext{
A. K. Leist $(\bowtie)$

Faculty of Language and Literature, Humanities, Arts and Education, University of Luxembourg, Research Unit INSIDE, Route de Diekirch, 7220 Walferdange, Luxembourg e-mail: anja.leist@uni.lu
}
A. K. Leist
Department of Public Health, Erasmus Medical Centre, Rotterdam, The Netherlands
D. Müller
University of Trier, Trier, Germany 
might help in overcoming a stressful life situation. Humor, conceptualized as a habitual behavior pattern with the general tendency to laugh or tell funny stories, is a multifaceted construct that might be used, for example, to cheer up others as well as oneself or to engage in personal relations (see Martin et al. 2003, for a review of literature). One might also differentiate humor-related behaviors by the manner in which the humor is delivered, for example, if humor is used to devaluate oneself or others or to appraise one's or others' abilities, respectively. The manner in which humor is delivered is widely accepted as disposition and therefore as certain style of humor. There is reason to believe that humor plays an important role in explaining well-being. Several sayings, like the one introduced earlier, remind us of the "healing nature of laughter" or the effectiveness of "coping with humor". Empirical evidence, particularly by Martin et al. (2003), shows important associations of humor styles with well-being. However, humor as a psychological construct is characterized by styles that are closely interrelated but not equally adaptive for well-being (e.g., Martin et al. 2003; Ruch 2007). By investigating different constellations of humor styles, new associations might emerge and advance the understanding of humor styles and their association with well-being. Therefore, the present study will develop and use a typology of humor styles similar to the approach of Galloway (2010). Building upon the framework of Martin et al. (2003), and in an attempt to further clarify the associations between humor styles and their contribution to promote well-being, this contribution will investigate how humor types are related to self-regulatory strategies, quality of life, and well-being.

\subsection{Typology of Humor Styles}

To assess differences in humor styles, Martin et al. (2003) developed the Humor Styles Questionnaire (HSQ), an instrument designed to assess habitual humor-related behavior patterns, that is, different styles of humor. They distinguish four humor styles on the two continua "humor to enhance self versus relationships with others" and "benign versus potentially detrimental humor". To define these humor styles, Martin et al. (2003) illustrate the humor styles with their potential outcomes in terms of well-being and social interactions. Firstly, affiliative humor reflects a humor style that is used to enhance one's relationships with others in a relatively benign way. It is the tendency to tell jokes and funny stories, in order to amuse and laugh with others. Self-enhancing humor refers to humor to enhance the self in a tolerant way and is the tendency to maintain a humorous outlook on life to cheer oneself up (Kuiper et al. 1993). Aggressive humor is a hostile form of humor to enhance the self at the expense of others and included sarcastic or criticizing humor. Lastly, self-defeating humor is used to enhance relationships with others at the expense and detriment of the self. A self-defeating use of humor is to make fun of oneself for the enjoyment of others, that is, to use humor in a self-disparaging way, or laughing along with others when being made fun of (cf. Chen and Martin 2007). Although there are many concurrent approaches that aim at assessing humor as a form of creativity, i.e., productive ability (e.g., Brodzinsky and Rubien 1976) or as moral value (Ruch et al. 2010a, b), dispositional humor styles have been found to be validly assessed by the HSQ. For example, humor styles have been shown to distinctly correlate with the "dark triad" traits of personality, namely aggressive humor with narcissism, Macchiavellism, and psychopathy (Veselka et al. 2010). However, it is unclear why only singular, one-dimensional associations of humor styles with well-being and personality measures have been investigated to date. First, one-dimensional associations of humor styles with well-being might be inconclusive because different motivational strivings could underlie the use of humor. 
For example, aggressive humor can be seen as antisocial and detrimental for social interactions, but could also be useful in enhancing one's feelings of being superior to others or useful in keeping one's place in the social hierarchy, which both might involve a sense of competence, control, and well-being. Self-defeating humor, as a second example, might be useful to (re)negotiate one's place in the social hierarchy, to amuse others by making a fool of oneself, and therefore, in general, to affiliate with others. In this line of reasoning, different humor styles might be combined according to motivational strivings. Second, one-dimensional approaches might be less fruitful than multi-dimensional approaches considering that it is highly implausible that individuals make use of only one certain distinct humor style. Nonetheless, there are-to the best of our knowledge-no assumptions about individual patterns in the use of humor styles. Thus, an exploration of the individual differences in combining the four humor styles would certainly enhance knowledge in this domain. A study conducted parallel to the present contribution provided valuable results in an Australian sample on regrouping humor styles into more broader categories of humor types (Galloway 2010). Galloway showed several associations of the humor types with personality trait measures as a means to explain humor types. A further comparison of the present and Galloway's study will be provided in more detail later. In sum, there are several reasons for preferring multi-dimensional over one-dimensional approaches in the investigation of humor styles, which should thus not be considered as beneficial or detrimental per se. In the present contribution, we therefore aim at further enhancing knowledge on the combinations of dispositional humor styles by investigating which combinations of humor styles exist and thus to develop a typology of humor styles. Investigating the assocations of these humor types with quality of life and well-being measures might advance the understanding of the contribution of humor in explaining quality of life and well-being.

\subsection{Humor and Well-Being}

Concerning the beneficial versus detrimental nature of humor, what do we know about the associations between humor and well-being so far? Empirical evidence on links between physical health, humor, and laughter is "weak and inconclusive" (Martin 2001) and some components of humor even seem detrimental for physical health (Kerkkanen et al. 2004). However, much research has been conducted concerning the associations between components of humor and psychological well-being (e.g., Kuiper et al. 2004; Lefcourt and Thomas 1998; Marziali et al. 2008; Olson et al. 2005; Thorson and Powell 1993; Yip and Martin 2006). In general, humor seems to facilitate psychological health and well-being (Thorson et al. 1997) and seems to buffer the impact of stressful life events (Nezu et al. 1988). The positive relationship between sense of humor and well-being is moderated by personality constructs, for example feelings of agency and communion (Kuiper and Borowicz-Sibenik 2005). Also, humor styles have been shown to mediate the association between self-evaluative standards and psychological well-being (Kuiper and McHale 2009). In the present study, we will focus on humor styles and take into account Martin et al.'s findings (2003): They examined the four humor styles regarding their associations with well-being and found multiple significant associations with different well-being measures, especially for selfenhancing and affiliative humor. There, affiliative humor was positively associated to measures of well-being and self-esteem, and negatively related to anxiety and depression. Self-enhancing humor showed the same, and an even stronger, correlation pattern, but was also significantly associated with optimism. Aggressive humor was associated with aggression and hostility, but not with well- or ill-being measures of any kind. Self-defeating 
humor, lastly, correlated highly positively with anxiety, depression, hostility, aggression, and psychiatric and somatic symptoms, and, negatively, with self-esteem and well-being. These correlation patterns have for the most part been replicated in an Armenian sample (Kazarian and Martin 2006). However, aside from findings on straightforward associations of humor styles with well-being and pathology, it is unclear to which extent individuals are equipped with different combinations of humor styles and if these combinations of humor styles show different associations with well-being. It is highly plausible, considering the moderate, but not too strong associations between the humor styles, that individuals differ in the constellations of humor styles. Differential constellations of humor styles might lead to differential associations with well-being. For example, it is intuitively likely that high levels of aggressive humor in combination with high self-enhancing humor are beneficial, whereas aggressive humor in combination with high self-defeating humor is detrimental for wellbeing. However, these differential associations might not be visible in correlative, meanlevel analyses. Therefore, we believe that it is important to use a person-centered, typological approach to investigate combinations of humor styles, that is, humor types. These humor types will then be investigated with regard to associations with different well-being measures. First, self-esteem has been found to be an important resource for well-being dependent upon humor styles (Martin et al. 1993). The construct life satisfaction, also investigated earlier in humor research, represents the cognitive-evaluative component of quality of life or well-being (Diener et al. 1985). Further extending the study of humor and its associations with self-esteem and well-being, we were interested in examining associations of humor and self-regulatory strategies. Self-regulatory strategies are behavior patterns concerning the pursuit of goals and can be differentiated in the general tendencies to pursue goals even in the face of obstacles (tenacious goal pursuit) or to adjust personal goals when faced with situational constraints (flexible goal adjustment; Brandtstädter and Renner 1990). To our knowledge, no study has investigated the associations of humor styles and self-regulatory strategies yet. Self-regulatory strategies have been conceptualized as resources that have been shown to be differentially associated with well-being (Brandtstädter and Greve 1994; Forstmeier and Maercker 2008; Wrosch et al. 2003). Self-regulatory strategies are regarded as important precursors to well-being even in the face of adverse circumstances (Brandtstädter and Greve 1994). Both self-regulatory strategies and humor styles have been conceptualized as disposition "buffering" stressful events and as means to cope with adversities. Further, both affiliative and self-enhancing humor styles and flexible goal adjustment share a positive reinterpretation of a (perhaps adverse) situation. Therefore, it can be assumed that affiliative and self-enhancing humor styles (and humor types characterized by these styles) are positively associated with flexible goal adjustment. The relationship of humor styles and humor types with tenacious goal pursuit will be investigated without specific assumptions.

\section{Research Questions}

Our study is guided by three steps: First, the structure of the Humor Styles Questionnaire found by Martin et al. (2003) will be replicated in a German sample to ensure comparability of results. Secondly, patterns of humor styles will be investigated guided by the question if individuals can be grouped according to different combinations of the four humor styles and develop a typology of humor styles. Lastly, the research question will be explored if humor types differ with respect to associations with self-regulatory strategies, and in their contribution to explaining self-esteem and well-being. 
Table 1 Description of the sample concerning age and relationship status for men and women

\begin{tabular}{lll}
\hline & Men $(n=97,28.4 \%)$ & Women $(n=245,71.6 \%)$ \\
\hline Mean age & 30.04 & 27.68 \\
Age range & $17-73$ & $15-67$ \\
Relationship status & Single $n=43(44.3 \%)$ & Single $n=88(35.9 \%)$ \\
& In relationship $n=37(38.1 \%)$ & In relationship $n=114(46.5 \%)$ \\
& Married $n=17(17.5 \%)$ & Married $n=42(17.1 \%)$ \\
& Divorced $n=0(0.0 \%)$ & Divorced $n=1(0.3 \%)$ \\
\hline
\end{tabular}

This research question was investigated in a sample of adolescents and adults in young and middle adulthood. In exploratory and confirmatory analyses, the factor structure of the HSQ was investigated. Secondly, with hierarchical clustering, three humor types were identified. Lastly, in analyses of variance, the associations between humor types, selfregulatory strategies, self-esteem, and well-being were examined.

\section{Method}

\subsection{Data Collection}

Data collection took place within the work on the diploma thesis of the second author. Due to time limitations, the convenience sample was acquired through e-mail distribution of a link to the online questionnaire. ${ }^{1}$ A total of 348 individuals participated in the study. Data of three persons were eliminated because of too short duration of processing the questionnaire and another three persons because of missing data. So, the data of $N=342$ participants could be used. Reported age ranged from 15 to 73 years $(M=28.35$ years, $\mathrm{SD}=10.52$ ). However, after data screening and due to the nonnormal distribution of the age variable (see below), data of $N=305$ individuals with an age range of 15-40 years were retained for exploratory and confirmatory factor analyses. Slightly different sample sizes are due to some randomly missing data in the self-regulation inventory (Brandtstädter and Renner 1990, see below). A total of 218 participants were female (71.6\%). When asked for relationship status, $44.2 \%$ reported to be in a relationship, $38.3 \%$ to be single, $17.3 \%$ to be married, and $0.3 \%$ were divorced. In Table 1, age range and relationship status are presented for men and women.

Participants were asked to report their professional status or their profession, respectively. Unfortunately, no information about educational status was available. Therefore, information on profession was recoded with regard to jobs requiring a graduate degree or not. According to this information, more than half of the sample were students $(n=193$, $56.4 \%)$ and $n=83(24.3 \%)$ were employed in jobs without graduate degree. A total of 40 participants $(11.7 \%)$ worked in jobs requiring a university degree, $n=11(3.2 \%)$ were students in a secondary school (comparable to a US high school or college), $n=6(1.8 \%)$ were retired, and $n=4(1.2 \%)$ in an apprenticeship.

\footnotetext{
${ }^{1}$ Weaknesses of online surveys concern the perception of the online questionnaire as junk mail, as impersonal, or the low response rate (Evans and Mathur 2005). However, those weaknesses were overcome by the distribution of the link to the online questionnaire via personal invitation and by publication in the university newsletter with a remark that questionnaire data were basis for a diploma thesis and only used for scientific purposes.
} 


\subsection{Instruments}

\subsubsection{Self-Esteem}

The revised German version of the Rosenberg Self-Esteem Scale was used (Ferring and Filipp 1996; Von Collani and Herzberg 2003). An example item is "All in all, I am satisfied with myself". The widely used scale contains 10 items with a four-point response format and the anchors not at all true and completely true $(M=3.17, \mathrm{SD}=0.54$, $\alpha=.90)$.

\subsubsection{Self-Regulatory Strategies}

We used an instrument developed by Brandtstädter and Renner (1990) to assess selfregulative strategies in German language. We administered the scales tenacious goal pursuit (TEN) and flexible goal adjustment (FLEX), each containing 15 items. Tenacious goal pursuit reflects an assimilative tendency to "adjust developmental situations to personal preferences" (Brandtstädter and Renner 1990, p. 64). An example item for tenacious goal pursuit is "The harder a goal is to achieve, the more desirable it often appears to me" $(M=3.42, \mathrm{SD}=0.58, \alpha=.85)$. Flexible goal adjustment is an accommodative tendency and measures the extent to which one adjusts personal preferences to situational constraints. An example item for flexible goal adjustment is "I can adapt quite easily to changes in a situation" $(M=3.37, \mathrm{SD}=0.57, \alpha=.85)$. Respondents were asked to rate their agreement with the items on a five-point rating scale with the end points not at all true and completely true.

\subsubsection{Well-Being}

The widely used Satisfaction with Life Scale (Pavot and Diener 1993) was administered. The scale contains five items with a seven-point rating scale with the anchors totally disagree and totally agree $(M=4.87, \mathrm{SD}=1.37, \alpha=.86)$. An example item is "I am satisfied with my life". All measures were presented with a response format providing only the scale anchors due to formatting issues. Descriptives, internal consistencies, and interrelations of self-regulatory strategies, self-esteem and well-being are also presented in Table 2. Interrelations were highly significant, which is to be expected regarding the already mentioned relations between the constructs.

Table 2 Descriptive statistics and internal consistencies of self-regulatory strategies, self-esteem, and wellbeing measures $(\mathrm{N}=294-305)$

\begin{tabular}{|c|c|c|c|c|c|c|c|c|}
\hline & \multicolumn{4}{|c|}{ Descriptives } & \multicolumn{4}{|c|}{ Correlations } \\
\hline & Min & $\operatorname{Max}$ & M & SD & SE & TEN & FLEX & LS \\
\hline Self-esteem (SE) & 1.20 & 4.00 & 3.17 & 0.54 & .90 & & & \\
\hline TEN & 1.67 & 4.73 & 3.42 & 0.58 & $.49 * * *$ & .85 & & \\
\hline FLEX & 1.27 & 4.67 & 3.37 & 0.57 & $.44 * * *$ & $.18 * *$ & .85 & \\
\hline Life satisfaction (LS) & 1.40 & 7.00 & 4.87 & 1.24 & $.65^{* * *}$ & $.33 * * *$ & $.41 * * *$ & .86 \\
\hline
\end{tabular}

$* p<.05 ; * * p<.01 ; * * * p<.001$. Internal consistencies (Cronbach's alpha) in diagonals of correlation matrix. TEN tenacious goal pursuit, FLEX flexible goal adjustment 


\subsubsection{Humor Styles}

We administered a German version of the Humor Styles Questionnaire, translated by the second author. The translation was checked by a native English speaker. The Humor Styles Questionnaire contains 32 items, each of the four scales consists of 8 items (see Martin et al. 2003, for the original scales; see Müller 2009, for the German version). Respondents rated their agreement with the items on a seven-point rating scale (totally disagree-totally agree).

\subsection{Strategy of Data Analysis}

Data screening revealed a nonnormal distribution of the age variable since only $10 \%$ of the sample was aged over 40 years $(n=37)$. With respect to interpretability of results, a transformation of this variable was considered to be contraindicated. The exploratory and confirmatory factor analyses were conducted for the whole sample. However, to exclude age as a possible confound and to acknowledge potential developmental changes in humor styles and associations with well-being over the life course, we used a subsample of participants aged up to 40 years for cluster and variance analyses. In this subsample, age was normally distributed. This subsample consisted of $N=305$ participants aged $15-40$ years $(M=25.17, \mathrm{SD}=4.60)$. Supporting the assumption of age-differences over the life course and the strategy of investigating a less age-heterogeneous sample, differences between retained and screened sample emerged in the way that affiliative humor scores were higher, whereas scores of aggressive humor were lower in the screened sample (both $p$ values <.001). Other differences did not get significant. Age-related differences in humor styles will be discussed below.

Firstly, to examine the underlying structure of the Humor Styles Questionnaire, exploratory and confirmatory factor analyses with the whole sample were performed. Secondly, differential constellations of humor styles, so called humor types, were investigated. Therefore, in order to find different humor types, hierarchical clustering was performed. Lastly, to answer the research question on whether humor types differ in self-regulatory strategies, self-esteem, or well-being, analyses of variance (ANOVAs) and post hoc tests were performed. Analyses were carried out with Amos 17.0 and PASW (former SPSS) 18.0.

\section{Results}

\subsection{Factor Structure of the German HSQ}

To ensure validity of the HSQ, we aimed at comparing the underlying factor structure of the HSQ in our German sample with Martin et al.'s (2003) findings. Assumptions for data analysis with exploratory and confirmatory factor analyses were met. The 32 items of the German version of the HSQ were factor analyzed with exploratory factor analysis (principal axis factoring and varimax rotation). Firstly, after running an exploratory factor analysis, a factor solution emerged that was highly consistent with Martin et al.'s (2003) findings. As in the Canadian sample, according to the scree plot a four factor solution seemed optimal that explained $45.8 \%$ of the total variance. The first four initial eigenvalues were $6.18,3.84,2.75$, and 1.89 (the next three eigenvalues were 1.3, 1.2, and 1.0). Items loaded on the same factors as presented in Martin et al.'s (2003) analyses. Some, mainly minor, differences in factor loadings were found: For items constituting the selfenhancing scale, item 30 ("I don't need to be with other people to feel amused-I can 
usually find things to laugh even when I'm by myself") had a significant factor loading in the original but not in the German sample $\left(a_{G}=.16\right.$ vs. $\left.a_{o r}=.58\right)$. For the scale aggressive, items 11 and 19 ("When telling jokes or saying funny things, I am usually not very concerned about how other people are taking it" and "Sometimes I think of something that is so funny that I can't stop myself from saying it, even if it is not appropriate for the situation") showed slightly lower factor loadings in the German sample ( $a_{G}=.33$ vs. $a_{o r}=.53$; and $a_{G}=.26$ vs. $a_{o r}=.48$, respectively). In fact, item 19 had a slightly higher loading on the factor constituted by items of affiliative humor $\left(a_{G}=.34\right)$. However, items of the scale self-defeating and affiliative were all similar in value and significance. Additionally, a confirmatory factor analysis was carried out that tested the model of Martin et al. (2003). Hu and Bentler (1999) suggest to accept RSMEA values close to .06 or below as reasonably good. The model showed acceptable fit (German sample: RMSEA $=.06$, CMIN/DF = 2.319). The indices in the German sample were only slightly lower than in Martin et al.'s findings (Canadian sample: RMSEA $=.05, \mathrm{CMIN} / \mathrm{DF}=3.37$ ).

\subsection{Descriptive Analyses}

The humor scales affiliative, self-enhancing, aggressive, and self-defeating were constructed according to the original HSQ scales presented in Martin et al. (2003). Internal consistencies of the German HSQ scales were moderate to good and comparable to findings of Martin et al. (2003). Participants scored highest on affiliative humor $(M=5.87$, $\mathrm{SD}=0.78 ; \alpha=.78)$, followed by self-enhancing humor $(M=4.60, \operatorname{SDSD}=1.04$; $\alpha=.83)$, and aggressive humor $(M=4.04, \mathrm{SD}=0.94 ; \alpha=.74)$. The lowest scores were found on self-defeating humor $(M=3.39, \mathrm{SD}=1.10 ; \alpha=.84)$. Most correlations between the German HSQ scales were quite similar to the original HSQ scales in absolute value and significance level (see Table 2). However, two notable differences in the correlation pattern emerged: While the original affiliative and self-defeating scales were not correlated, we found a small association of the scales in the German sample $(r=.13$, $p<.05)$. Similarly, self-enhancing and self-defeating humor did not correlate in the original study, whereas in the German sample, we found a quite remarkable association $(r=.18, p<.01)$. Descriptive statistics are reported in Table 3 .

\subsection{Cluster Analysis}

In a next step, it was examined with cluster analysis whether different patterns of humor styles could be differentiated and could be thus regrouped into humor types. We z-standardized the humor style scales to facilitate interpretation of findings. These z-scores were entered as grouping variables in a hierarchical cluster analysis with squared Euclidean distance and Ward's algorithm. The three-cluster solution proved to be most stable when running analyses with the whole and the screened sample and to be most compelling in both parsimony and interpretability of the clusters. The first cluster was characterized by an above average amount of all four humor styles (humor endorsers, $N=134,43.9 \%$ ), the second cluster had below average scores in all humor styles, especially very low selfenhancing humor (humor deniers, $N=109,35.7 \%$ ), and the third cluster was characterized by slightly above average affiliative humor, highly above average self-enhancing humor, and below average aggressive and self-defeating humor (self-enhancers, $N=62$, $20.3 \%$ ). Z-standardized values for each of the three clusters are presented in Table 4 and Figure 1. We validated the three-cluster solution with k-means clustering. In a second cross-validation procedure, we divided the sample at random in two subsamples with 





Table 4 Descriptive statistics (means and standard deviations) of z-standardized HSQ humor styles for the three humor types $(\mathrm{N}=305)$

\begin{tabular}{llll}
\hline & \multicolumn{2}{l}{ Cluster } & \\
\cline { 2 - 4 } & $\begin{array}{l}\text { Humor endorsers } \\
\text { M (SD) }\end{array}$ & $\begin{array}{l}\text { Humor deniers } \\
\text { M (SD) }\end{array}$ & $\begin{array}{l}\text { Self-enhancers } \\
\text { M (SD) }\end{array}$ \\
\hline Affiliative & $0.51(0.61)$ & $-0.53(1.10)$ & $0.27(0.71)$ \\
Self-enhancing & $0.61(0.75)$ & $-1.01(0.72)$ & $0.57(0.48)$ \\
Aggressive & $0.65(0.87)$ & $-0.15(0.85)$ & $-0.77(0.64)$ \\
Self-defeating & $0.72(0.77)$ & $-0.31(0.84)$ & $-0.91(0.63)$ \\
\hline
\end{tabular}

Fig. 1 Values of HSQ humor styles in the three humor types

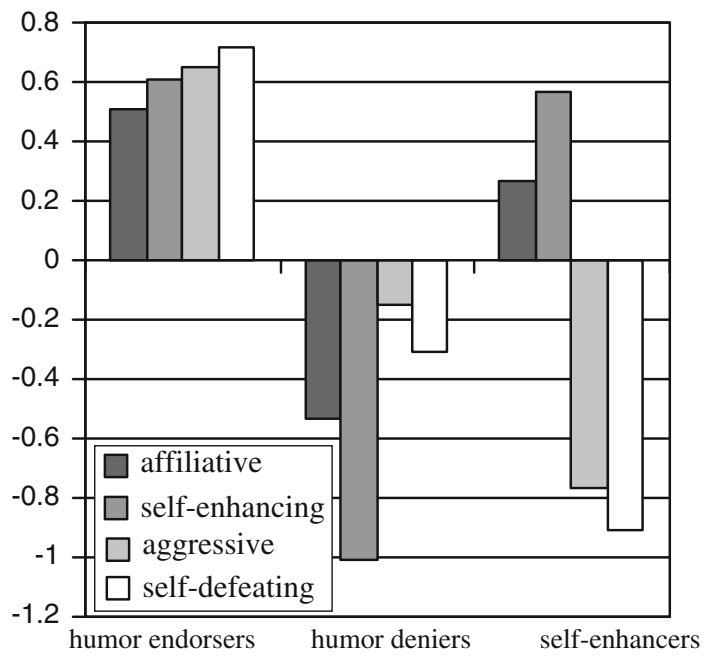

approximate $50 \%$ of the cases and conducted additional hierarchical cluster analyses in the subsamples. ${ }^{2}$ In both subsamples $\left(n_{1}=147\right.$ and $\left.n_{2}=158\right)$, a highly similar threecluster solution emerged, which also mirrored the cluster results in the total sample. In this solution, the first cluster showed above average levels in all humor styles $\left(n_{1}=52\right.$ and $\left.n_{2}=82\right)$, a second cluster showed below average levels in all humor styles $\left(n_{1}=57\right.$ and $n_{2}=52$ ) and a third cluster showed slightly above average affiliative humor, highly above average self-enhancing humor and below average self-defeating and aggressive humor $\left(n_{1}=38\right.$ and $n_{2}=24$ ). One can fairly conclude by these results that the initial cluster solution proved useful in the cross-validation procedure and we used this solution for further analyses.

We checked for age and gender differences in the three clusters. The clusters did not differ in age of the individuals, $F(2,302)=2.05, p=.13$; nor in gender distribution between clusters, Cramèr's $V=.13, p=.09$.

\footnotetext{
${ }^{2}$ We thank an anonymous reviewer for the suggestion of cross-validation in subsamples.
} 


\subsection{Correlates of Humor Types}

In a next step, associations between humor styles, self-regulatory strategies, self-esteem, and well-being were investigated. Zero-order correlations of the humor scales, self-regulatory strategies, self-esteem, and well-being are presented in Table 3. Whereas affiliative and self-enhancing humor were highly positively correlated with self-regulatory strategies, life satisfaction, and well-being, aggressive humor showed null correlations with all measures but a small negative correlation with flexible goal adjustment. Also, selfdefeating humor was not related with flexible goal adjustment and life satisfaction.

Finally, to examine associations of humor clusters, the so called humor types, with the well-being variables, self-esteem, tenacious goal pursuit, flexible goal adjustment, and life satisfaction were tested for mean differences between the three clusters (see Ferring et al. 2009, for an example using a comparable methodological approach). We performed univariate analyses of variance (ANOVAs) for each dependent variable (DV), with apportionment of $\alpha=.01$. Post hoc tests were carried out; presented here are results of the Bonferroni test that corrects error probability for the number of compared groups. Since the DVs assess related constructs with significantly overlapping variance (see correlations in Table 2), for the post hoc tests alpha was also set to .01. For self-esteem, tenacious goal pursuit, and flexible goal adjustment, homogeneity of error variances was given. Since error variances for life satisfaction were unequal (Levene's Test, $p<.05$ ), a robust Welch test was performed. This test does not require variance homogeneity. Since there were no differences in error probabilities between ANOVA and Welch test, only the results of the ANOVAs are presented here. To test for cluster differences in life satisfaction, the post hoc test Tamhane's T2 test was carried out, which also does not require variance homogeneity. The results concerning self-esteem, self-regulatory strategies, and life satisfaction will be presented separately.

We found significant group differences in self-esteem, $F(2,302)=15.75, p<.001$. Self-enhancers and endorsers as well as self-enhancers and humor deniers types differed significantly (both $p$ values $<.01$ ), in the sense that endorsers had an average score on selfesteem, humor deniers a below average score, and self-enhancers an above average score. The difference between humor endorsers and humor deniers did not quite reach significance $(p=.01)$. Humor types also showed differences on tenacious goal pursuit, $F(2$, $302)=8.42, p<.001$. Only humor deniers and self-enhancers differed significantly $(p<.01)$, whereas the other comparisons did not reach significance $(p=.04)$. Like on self-esteem, endorsers had average scores, humor deniers below average, and selfenhancers above average on tenacious goal pursuit. Considering flexible goal adjustment, humor types differed significantly, $F(2,302)=18.26, p<.001$. While humor endorsers and self-enhancers did not show differences in flexible goal adjustment $(p=.63)$, the other comparisons were significant $(p<.001)$ : Humor deniers scored below average, humor endorsers on average, and self-enhancers had the highest values on flexible goal adjustment. Lastly, considering life satisfaction, humor types differed significantly in amount of life satisfaction, $F(2,302)=11.53, p<.001$. In particular, humor deniers and humor endorsers as well as self-enhancers differed significantly (both $p$ values $<.01$ ), whereas humor endorsers and self-enhancers did not differ in amount of life satisfaction $(p=.20)$. The z-standardized values of the DVs self-esteem, tenacious goal pursuit, flexible goal adjustment, and life satisfaction for each cluster are presented in Table 5 and plotted in Fig. 2.

In an attempt to quantify the effect sizes of variance in the well-being measures explained by the humor types compared with humor styles, we calculated $R$ from several 
Table 5 Means and standard deviations of z-standardized DVs for the humor types

\begin{tabular}{llrl}
\hline & \multicolumn{2}{l}{ Cluster } & \\
\cline { 2 - 4 } & Endorsers & Humor deniers & $\begin{array}{l}\text { Self- } \\
\text { enhancers }\end{array}$ \\
\hline$N$ & $134,43.9 \%$ & $109,35.7 \%$ & $62,20.3 \%$ \\
\hline Self-esteem & M (SD) & M (SD) & M (SD) \\
TEN & $0.00(1.00)$ & $-0.36(1.05)$ & $0.51(0.80)$ \\
FLEX & $0.04(0.97)$ & $-0.23(1.01)$ & $0.40(0.91)$ \\
Life satisfaction & $0.14(0.98)$ & $-0.48(1.00)$ & $0.32(0.80)$ \\
& $0.06(0.88)$ & $-0.23(1.10)$ & $0.32(0.95)$ \\
\hline
\end{tabular}

TEN tenacious goal pursuit, FLEX flexible goal adjustment

Fig. 2 Correlates of humor types with self-regulatory strategies, self-esteem and well-being

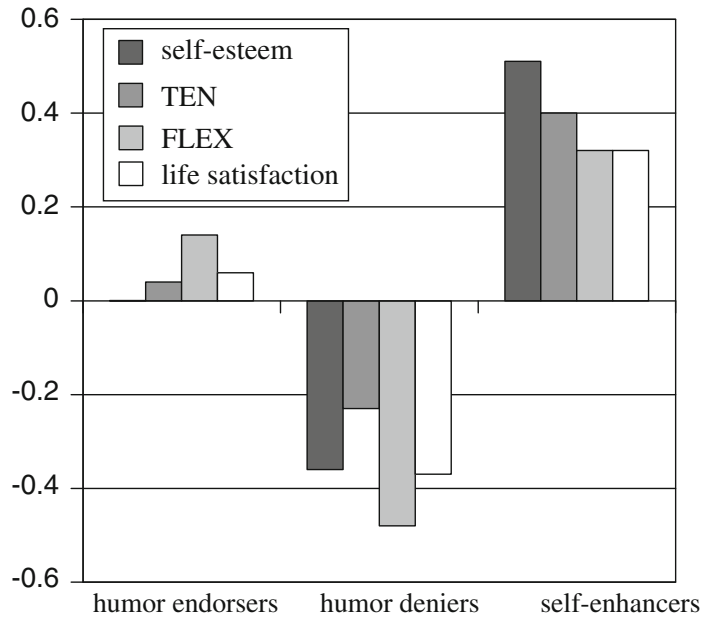

Table 6 Effect sizes of associations of dichotomized humor scales and humor type with well-being measures

\begin{tabular}{llllll}
\hline & \multicolumn{2}{l}{ Dichotomized humor scales } & & Humor type \\
\cline { 2 - 5 } & Affiliative & Self-enhancing & Aggressive & Self-defeating & \\
\hline Self-esteem & 0.016 & 0.028 & 0.001 & 0.012 & 0.047 \\
TEN & 0.004 & 0.020 & 0.000 & 0.001 & 0.035 \\
FLEX & 0.002 & 0.089 & 0.003 & 0.001 & 0.054 \\
Life satisfaction & 0.018 & 0.012 & 0.005 & 0.012 & 0.026 \\
\hline
\end{tabular}

Effect sizes (R) derived by dividing sum of squares between groups by total sum of squares. TEN tenacious goal pursuit, FLEX flexible goal adjustment

ANOVAs with humor type (presented above) and the dichotomized humor scales, respectively, as factors. As Table 6 shows, aside from self-enhancing humor (low versus high) explaining a larger amount of variance in flexible goal adjustment than humor type 
( $R=0.089$ compared to $R=0.054$ ); all other comparisons show a larger effect size of the associations of humor type with the well-being measures compared to humor styles, showing thus an advantage of investigating humor types instead of single humor scales.

\section{Discussion}

\subsection{Factor Structure of the HSQ and Equivalence of the German and the Original HSQ}

Firstly, to ensure validity of the findings gained with the HSQ in a German sample, findings of Martin et al. (2003) concerning the factor structure of the Humor Styles Questionnaire were compared and replicated in an age-heterogeneous sample in adolescence, and young and middle adulthood.

The adequacy of the German and English version of the HSQ was confirmed with exploratory and confirmatory factor analyses, showing that fit indices were only slightly different from Martin et al.'s (2003) model. One difference emerged in the fact that the self-defeating humor was to a small extent correlated with both affiliative and selfenhancing humor in the German sample, but did not correlate in the original sample. Since the exploratory factor analytic results are highly comparable to earlier studies on the HSQ and the correlations are rather small, it cannot totally be excluded that the different correlation patterns might represent a sample-specific finding. It might even represent methodspecific common variance induced by similar wording, although the translation process had been carried out carefully to prevent similar wording. Having ruled out alternative explanations, it might also be the case that the differences in the correlations of the humor styles reflect cultural differences between the original Canadian and the German sample. It has been shown that humor styles differ between cultures, however these investigations drew comparisons between Western and Eastern and Western and Arabic societies, respectively (e.g., Chen and Martin 2007; Kalliny et al. 2006). Therefore, with both studies relying on a sample of individuals of a Western society, one might suggest only small differences between the Canadian and the German sample. A possible explanation is that self-defeating humor is a common way of interaction for younger Germans; it might be a culture-specific expectation in Germany to be able to laugh or make jokes about oneself. Self-defeating humor might thus not necessarily be maladaptive in Germans as suggested by Martin et al. (2003). However, to our knowledge, specific differences in humor understanding between Canadians and Germans have not been investigated yet and would desire a qualitative study investigating the meaning and reception of self-defeating humor in both cultures.

\subsection{Humor Types and Well-Being}

To regroup humor styles into the broader constellation of humor styles, namely humor types, a cluster analytic procedure was carried out. We found one type endorsing humor, one type refusing to use humor, and one type using humor to enhance the self. Humor styles were only to a small extent related to well-being. This points to the fact that humor scales are not per se detrimental or beneficial, but have to be investigated within the context of other humor styles and, perhaps, their situational dependency. Humor types were related with well-being measures in a more coherent way and seemed more easy to interpret than the associations of humor styles, which might once again justify the methodological approach used in this study. Nonetheless, the results have to be regared with 
caution, since the sample was composed to more than two thirds by women and one can thus only carefully draw broad conclusions.

The humor type-well-being relationships shall be described next before drawing further inferences. The first humor type, "humor endorsers", showed across all humor scales high scores (i.e., above average), which characterized a third of the sample (35.7 \%). This might reflect cheerfulness and generalized behavior patterns to make jokes, see "the funny side of life" or to not take life too seriously. On the other hand, it might characterize a behavior pattern that uses humor carelessly or without further reflection, to use jokes and funny remarks with means that might even be harmful for oneself or another person. This possible explanation was validated by the analyses of variance: Humor endorsers showed average levels of self-regulatory strategies, self-esteem, and well-being. Even though the cross-sectional associations must not be interpreted in a causal way, one might infer that high levels of humor endorsers are not especially beneficial for well-being. This finding particularly advances the understanding of earlier mono-dimensional results of relations between humor styles and well-being (e.g., Martin et al. 2003): Despite high levels of selfenhancement, the well-being pattern for endorsers is not particularly adaptive.

The second humor type, "humor deniers", showed below average levels of humor styles, but especially low self-enhancing humor. This pattern reflects a behavior pattern that humor is seldom used to cheer oneself up. The humor deniers showed lowest levels of self-regulatory strategies, self-esteem, and well-being, implicating that this humor type is not beneficial for well-being either.

Thirdly, the humor type "self-enhancers" was characterized by below average aggressive and self-defeating humor, average affiliative humor, and clearly above average self-enhancing humor. This reflects a humor type that focuses on humor to make oneself feel better even when not in the company of others. Analyses of variance showed impressively that this type might be most adaptive: On all measures of self-regulatory strategies, self-esteem, and well-being, self-enhancers scored highest. This finding showed that a self-enhancing humor style might be most beneficial for well-being and underlines the adaptive correlates of self-defeating and aggressive humor being absent.

At this point, the findings shall be compared to the original intent to construct beneficial and detrimental humor styles in the HSQ (Martin et al. 2003). It seems noteworthy that the functional distinction between beneficial and detrimental humor is not reflected in the cluster analytic results and we address this issue with three arguments. Firstly, by replicating the factor structure of the HSQ in the German sample, we can fairly rule out the assumption that failures in translation of the questionnaire might have caused these findings. Secondly, these results confirm our initial assumption that humor styles cannot be considered as beneficial or detrimental per se as these might be expressions of different underlying motivational strivings. Thirdly, in conceptualizing humor styles, it has been widely neglected that humor styles are to a certain extent context dependent. It might be opportune to use self-defeating humor in the working context, aggressive humor with friends, and affiliative humor in the family. These assumptions might explain why some individuals, the so-called humor endorsers, apparently use humor in an undifferentiated way-they might just adapt their humor styles according to the context. This conclusion however can only be drawn cautiously, since subjective justifications for using humor or context-dependent variations or stability of the humor styles, respectively, have not been assessed. Further studies should evaluate on the context dependency of humor styles to shed more light to the-apparently complex-associations of humor styles and well-being. In addition, studies not limited by a cross-sectional sample might also investigate the longitudinal associations between humor types and well-being; it might be the case that 
self-regulatory strategies act as mediators in the humor-well-being relationship. Another open issue for further consideration is the inclusion of indicators of negative well-being, like depression or anxiety, and investigate their associations with humor types.

In a further attempt to clarify the complex associations between humor styles and wellbeing, it is noteworthy to distance from the functional implications of humor styles, namely, their pre-defined associations with well-being. Instead, we looked into the item contents to elaborate on the structural components of the humor styles. ${ }^{3}$ First, the items constituting "affiliative humor" deal with the outcome of humorous behavior; humor is presented as a means to "make other people laugh". Also, five of the eight constituting items describe behaviors of affiliative humor being absent (reversely coded) and couldtheoretically - be affirmed by persons who are equipped with no humor style whatsoever. Compared with other concepts of humor, the concept of affiliative humor resembles closest to humor as strength of character (Peterson et al. 2005) or as moral value, belonging to the core virtue 'transcendence' (humor as liking to laugh and joke and bringing smiles to other people; Ruch et al. 2010b). Second, items constituting the scale "self-enhancing humor" deal-without exception-with the antecedents of humor, namely a feeling or state of being depressed, sad, alone, or upset. Humor, in this line of reasoning, is described as a means to cope. In sum, both humor styles resemble constructs that have been shown to be positively related with well-being. Third, items constituting the scale "aggressive humor" describe antisocial behaviors like teasing, offending, or criticizing someone with humor to enhance oneself. Again, four of the eight items are negatively formulated and could be affirmed by persons who do not see themselves as humorous persons. Lastly, the scale "self-defeating humor" is constituted by a total of eight items, of which five items describe the means "putting" oneself "down". Also, the outcomes of humor are described, namely, to make people, friends, and family laugh, like or accept the individual, and to keep one's "friends and family in good spirits". Thus, one can fairly say that self-defeating humor shows affiliative, morally valued components. In sum, on a structural level, the humor scales might contain multiple meanings. Consequently, instead of a functional distinction in beneficial and detrimental humor styles, a typological approach investigating humor types proved useful in our study. Thus, the study shows that examinations of bivariate associations considering humor styles and well-being do not show the "full picture" of the multifold associations between these constructs. This was also shown by comparing effect sizes of associations of humor types with well-being measures compared to the associations of humor scales. Aside from one advantage of humor scales (low versus high scores on self-enhancing humor contributing more to flexible goal adjustment than humor type), all other comparisons could be interpreted in favor of using humor types instead of humor scales. However, the importance of this quantification should not be overestimated, since the advantage of using humor types clearly lies in interpreting the contribution of humor styles in the context of the other styles. For instance, self-enhancing humor is present in both endorsers and self-enhancers, but the adaptive value of this humor style is only reflected in the absence of the maladaptive styles.

In addition, it would now be interesting to examine the practical implications of these humor types. With an experimental test, for example by presenting different scenarios in vignettes, one could clarify if humor types differ in their social and self-related responses to these scenarios. ${ }^{4}$ Another open research question would of course be the longitudinal associations between humor types and well-being, and the attempt to examine if

\footnotetext{
${ }^{3}$ We thank Prof. Willibald Ruch for this suggestion.

${ }^{4}$ We would like to thank an anonymous reviewer for this suggestion.
} 
self-enhancing humor is really "beneficial" in the causal sense, or if one or several third variables, for example extraversion, emotional stability, or optimism, cause the associations between self-enhancing humor and well-being.

\subsection{Age Differences}

We did not assume age differences due to the sample in adolescence and young adulthood, although age differences might occur at a later stage in life, when humor styles or humor types might be dependent upon the time horizon of the individual. In line with this reasoning, we did not find any age differences between the clusters. However, Martin et al.'s (2003) findings suggest age differences in humor styles. This may be due to the fact that age differences can only be found on the scale level, but not on the cluster level. In fact, on the scale level, a further analysis regarding the whole sample revealed that age was negatively related to affiliative humor $(r=-.30, p<.001)$ and aggressive humor $(r=$ $-.26, p<.001)$, but not to the other two humor scales. Also, the participants older than 40 years who had been screened from the sample due to unequal age distribution showed lower aggressive and higher affiliative scores compared to the younger participants. Thus, in general, older participants used humor less to enhance relationships with others or to devaluate others with humor, which is consistent with Martin et al.'s (2003) findings. Further studies with a larger older sample should be used to replicate this finding.

\subsection{Further Considerations}

Parallel to our study, Galloway has been investigating the combination of humor styles and their relations to the Big Five traits of personality characteristics. Applying a clustering method similar to our study, Galloway (2010) found four clusters with (1) above average scores on all humor styles, (2) below average scores on all humor styles, (3) above average on the positive styles and below average on the negative styles, and (4) above average on the negative styles and below average on the positive styles. In our study, two of the four clusters were comparable to those that had been found in the Australian sample by Galloway (2010), namely, the humor endorsers of cluster No. 1 and the humor deniers of cluster No. 2. Also, we found a cluster that showed high self-enhancing humor, average affiliative humor, and below-average negative humor styles. This pattern replicates the cluster solution of Galloway to a large extent. Considering the fact that the samples of the studies were both to a large part university students with a similar mean age, why did our study not totally replicate the findings of Galloway (2010)? Letting methodological caveats considering the translated questionnaire in our study aside, we cannot totally rule out crosscultural differences in interpreting the HSQ items. Concerning methodological arguments however, in our data, a fourth cluster solution was not stable and could not be crossvalidated. Therefore, we decided in favor of a three-cluster solution. This solution could both be cross-validated with another clustering method and in two randomly splitted subsamples.

In addition, Galloway (2010) examined associations of the four clusters with selfesteem. With the different number of clusters, the results are not totally comparable with our data. However, both studies showed that clusters low on affiliative and self-enhancing humor styles showing below-average self-esteem, whereas clusters high on these styles showing above-average self-esteem. Of the analyses both provided in this and Galloway's (2010) contribution, it can be concluded that especially the combination of self-enhancing and affiliative humor styles is related with self-esteem. 


\section{Conclusions}

In a German sample of young and middle aged adults, we found different humor types of the Humor Styles Questionnaire (Martin et al. 2003) via cluster analysis extending current bivariate approaches to the study of humor and well-being. Humor types were differentially associated with self-regulatory strategies, self-esteem, and well-being. Self-enhancers, characterized by high self-enhancing humor, mean affiliative, low aggressive, and low self-defeating humor showed most favorable associations with quality of life and wellbeing measures. In sum, these findings gained with a typological approach provide further evidence for self-enhancing humor as important resource for well-being, and especially underline the benefits when self-defeating and aggressive humor are absent.

Acknowledgments Data were collected within the framework of the second author's diploma thesis at the University of Trier, Germany (Müller 2009). The manuscript was prepared during a grant of the Fonds National de la Recherche Luxembourg to the first author. We thank Prof. Willibald Ruch for helpful comments and suggestions on an earlier draft of the manuscript. We would also like to thank three anonymous reviewers for their suggestions and Bernhard Baltes-Götz for helpful support in the implementation of the online questionnaire.

Open Access This article is distributed under the terms of the Creative Commons Attribution License which permits any use, distribution, and reproduction in any medium, provided the original author(s) and the source are credited.

\section{References}

Brandtstädter, J., \& Greve, W. (1994). The aging self: Stabilizing and protective processes. Developmental Review, 14(1), 52-80. doi:10.1006/drev.1994.1003.

Brandtstädter, J., \& Renner, G. (1990). Tenacious goal pursuit and flexible goal adjustment: Explication and age-related analysis of assimilative and accommodative strategies of coping. Psychology and Aging, 5(1), 58-67. doi:10.1037/0882-7974.5.1.58.

Brodzinsky, D. M., \& Rubien, J. (1976). Humor production as a function of sex of subject, creativity, and cartoon content. Journal of Consulting and Clinical Psychology, 44(4), 597-600.

Chen, G.-H., \& Martin, R. A. (2007). A comparison of humor styles, coping humor, and mental health between Chinese and Canadian university students. Humor, 20(3), 215-234. doi:10.1515/HUMOR. 2007.011.

Diener, E., Emmons, R. A., Larsen, R. J., \& Griffin, S. (1985). The satisfaction with life scale. Journal of Personality Assessment, 49(1), 71-75.

Evans, J. R., \& Mathur, A. (2005). The value of online surveys. Internet Research, 15(2), 195-219. doi: $10.1108 / 10662240510590360$.

Ferring, D., \& Filipp, S.-H. (1996). Messung des Selbstwertgefuehls: Befunde zu Reliabilitaet, Validitaet und Stabilitaet der Rosenberg-Skala [Measurement of self-esteem: Reliability, validity, and stability of the Rosenberg scale]. Diagnostica, 42(3), 284-292.

Ferring, D., Michels, T., Boll, T., \& Filipp, S.-H. (2009). Emotional relationship quality of adult children with ageing parents: on solidarity, conflict and ambivalence. European Journal of Ageing, 6, 253-265. doi:10.1007/s10433-009-0133-9.

Forstmeier, S., \& Maercker, A. (2008). Motivational reserve: Lifetime motivational abilities contribute to cognitive and emotional health in old age. Psychology and Aging, 23(4), 886-899. doi:10.1037/ a0013602.

Galloway, G. (2010). Individual differences in personal humor styles: Identification of prominent patterns and their associates. Personality and Individual Differences, 48, 563-567. doi:10.1016/j.paid.2009. 12.007.

Hu, L., \& Bentler, P. M. (1999). Cutoff criteria for fit indexes in covariance structure analysis: Conventional criteria versus new alternatives. Structural Equation Modeling, 6(1), 1-55. 
Kalliny, M., Cruthirds, K. W., \& Minor, M. S. (2006). Differences between American, Egyptian and Lebanese humor styles: Implications for international management. International Journal of Cross Cultural Management, 6(1), 121-134. doi:10.1177/1470595806062354.

Kazarian, S. S., \& Martin, R. A. (2006). Humor styles, culture-related personality, well-being, and family adjustment among Armenians in Lebanon. Humor: International Journal of Humor Research, 19(4), 405-423.

Kerkkanen, P., Kuiper, N. A., \& Martin, R. A. (2004). Sense of humor, physical health, and wellbeing at work: A three-year longitudinal study of Finnish police officers. Humor: International Journal of Humor Research, 17(1-2), 21-35.

Kuiper, N. A., \& Borowicz-Sibenik, M. (2005). A good sense of humor doesn't always help: Agency and communion as moderators of psychological well-being. Personality and Individual Differences, 38(2), 365-377.

Kuiper, N. A., Grimshaw, M., Leite, C., \& Kirsh, G. (2004). Humor is not always the best medicine: Specific components of sense of humor and psychological well-being. Humor, 17(1/2), 135-168. doi:10.1515/ humr.2004.002.

Kuiper, N. A., Martin, R. A., \& Olinger, L. J. (1993). Coping humour, stress, and cognitive appraisals. Canadian Journal of Behavioural Science, 25(1), 81-96. doi:10.1037/h0078791.

Kuiper, N. A., \& McHale, N. (2009). Humor styles as mediators between self-evaluative standards and psychological well-being. Journal of Psychology, 143(4), 359-376.

Lefcourt, H. M., \& Thomas, S. (1998). Humor and stress revisited. In W. Ruch (Ed.), The sense of humor: Explorations of a personality characteristic (pp. 179-202). Berlin: Mouton de Gruyter.

Martin, R. A. (2001). Humor, laughter, and physical health: Methodological issues and research findings. Psychological Bulletin, 127(4), 504-519. doi:10.1037/0033-2909.127.4.504.

Martin, R. A., Kuiper, N. A., Olinger, L. J., \& Dance, K. A. (1993). Humor, coping with stress, self-concept, and psychological well-being. Humor: International Journal of Humor Research, 6(1), 89-104. doi: 10.1515/humr.1993.6.1.89,//1993.

Martin, R. A., Puhlik-Doris, P., Larsen, G., Gray, J., \& Weir, K. (2003). Individual differences in uses of humor and their relation to psychological well-being: Development of the Humor Styles Questionnaire. Journal of Research in Personality, 37, 48-75. doi:10.1016/S0092-6566(02)00534-2.

Marziali, E., McDonald, L., \& Donahue, P. (2008). The role of coping humor in the physical and mental health of older adults. Aging and Mental Health, 12(6), 713-718.

Müller, D. (2009). Humorfacetten und deren Zusammenhaenge mit Wohlbefindensmaßen [Humor facets and their associations with well-being measures]. Unpublished diploma thesis. University of Trier, Trier, Germany.

Nezu, A. M., Nezu, C. M., \& Blissett, S. E. (1988). Sense of humor as a moderator of the relation between stressful events and psychological distress: A prospective analysis. Journal of Personality and Social Psychology, 54(3), 520-525.

Olson, M. L., Hugelshofer, P. K., \& Reff, R. C. (2005). Rumination and dysphoria: The buffering role of adaptive forms of humor. Personality and Individual Differences, 39, 1419-1428. doi:10.1016/ j.paid.2005.05.006.

Pavot, W., \& Diener, E. (1993). Review of the satisfaction with life scale. Psychological Assessment, 5(2), 164-172. doi:10.1037/1040-3590.5.2.164.

Peterson, C., Park, N., \& Seligman, M. E. P. (2005). Assessment of character strengths. In G. P. Koocher, J. C. Norcross, \& S. S. Hill III (Eds.), Psychologists' desk reference (pp. 93-98). New York: Oxford University Press.

Ruch, W. (Ed.). (2007). The sense of humor: Explorations of a personality characteristic. Berlin: Mouton de Gruyter.

Ruch, W., Proyer, R. T., \& Weber, M. (2010a). Humor as a character strength among the elderly: Empirical findings on age-related changes and its contribution to satisfaction with life. Zeitschrift für Gerontologie und Geriatrie, 43(1), 13-18. doi:10.1007/s00391-009-0090-0.

Ruch, W., Proyer, R. T., \& Weber, M. (2010b). Humor as a character strength among the elderly: Theoretical considerations. Zeitschrift für Gerontologie und Geriatrie, 43(1), 8-12. doi:10.1007/ s00391-009-0080-2.

Thorson, J. A., \& Powell, F. C. (1993). Development and validation of a multidimensional sense of humor scale. Journal of Clinical Psychology, 49, 13-23. doi:10.1002/1097-4679(199301)49:1<13:AID-JCL P2270490103>3.0.CO;2-S.

Thorson, J. A., Powell, F. C., Sarmany-Schuller, I., \& Hampes, W. P. (1997). Psychological health and sense of humor. Journal of Clinical Psychology, 53(6), 605-619. 
Veselka, L., Schermer, J. A., Martin, R. A., \& Vernon, P. A. (2010). Relations between humor styles and the Dark Triad traits of personality. Personality and Individual Differences, 48, 772-774. doi:10.1016/ j.paid.2010.01.017.

Von Collani, G., \& Herzberg, P. (2003). Zur internen Struktur des globalen Selbstwertgefuehls nach Rosenberg [The internal structure of global self-esteem according to Rosenberg]. Zeitschrift fuer Differentielle und Diagnostische Psychologie, 24(1), 9-22. doi:10.1024//0170-1789.24.1.3.

Wrosch, C., Scheier, M. F., Miller, G. E., Schulz, R., \& Carver, C. S. (2003). Adaptive self-regulation of unattainable goals: Goal disengagement, goal reengagement, and subjective well-being. Personality and Social Psychology Bulletin, 29(12), 1494-1508. doi:10.1177/0146167203256921.

Yip, J. A., \& Martin, R. A. (2006). Sense of humor, emotional intelligence, and social competence. Journal of Research in Personality, 40, 1202-1208. doi:10.1016/j.jrp.2005.08.005. 